\title{
BLENDER 3D UNTUK PENDIDIKAN ANIMASI
}

\author{
Mochamad Faizal Rochman \\ Dosen Program Studi Disain Komunikasi Visual \\ Jurusan Disain, FSR ISI Yogyakarta \\ Email: toxitbox@gmail.com
}

\begin{abstract}
Animation has become one of the pillars of the creative industries that have been set by the government. Animation is a major industry in addition to requiring a lot of human resources also requires greater availability of funds. The role of academia to create and educate human resources are necessary to meet the demands of the growing animation industry. Constraints in advancing educational animated classic one is the issue of availability of funds. Because the animation industry is an industry that requires the availability of hardware and software are very expensive.

This paper aims to ensure that the use of Free Open Source Software (FOSS) Blender 3D is very suitable to be applied in the world of education as an introduction to the study of three-dimensional animation.
\end{abstract}

Keywords: Blender 3D, animation education, open source

\section{Pendahuluan}

Cepatnya perkembangan animasi di Indonesia tidak lepas dari beberapa faktor yang mempengaruhi, salah satunya adalah internet. Percepatan teknologi internet yang tidak bisa dibendung kehadirannya merupakan salah satu faktor penentu cepatnya keberadaan industri animasi dikenal oleh masyarakat. Dengan mudahnya sekarang kita bisa melihat konten dan juga belajar animasi hanya dari internet. Pilihan perangkat lunak yang ingin digunakan juga beragam. Internet telah menyediakan segala sumber daya animasi yang dibutuhkan. Selain itu perkembangan televisi juga mempunyai dampak yang tidak bisa diremehkan dalam percepatan perkembangan animasi. Penayangan film-film animasi lewat saluran televisi memberikan dampak positif bagi perkembangan animasi di Indonesia. Tidak juga ketinggalan video game, PC game dan online game yang sekarang sedang menjamur dikalangan anak muda. Semua media tersebut tidak lepas dari konten animasi di dalamnya.

Dalam buku Studi Industri Kreatif Indonesia 2007 bagian 2, disebutkan bahwa pertumbuhan desain visual termasuk animasi, desain grafis, dan multimedia terus bergerak naik. Pertumbuhannya diperkirakan $10 \%-15 \%$ per tahun dengan market size diprediksi Rp. 5 triliun. Angka ini memang masih ketinggalan bila dibandingkan dengan India yang mencapai US\$ 1,5 miliar atau setara dengan Rp. 14 triliun hanya untuk industri animasinya yang pertumbuhannya mencapai $30 \%$ pertahun. Untuk mengejar ketinggalan dengan negara lain dalam bidang animasi, salah satu jalan yang bisa ditempuh adalah dengan mencetak animator-animator baru. Dunia pendidikan harus bisa memenuhi permintaan pasar tentang ketersediaan tenaga animator. Dan ini adalah tantangan yang sangat berat bagi dunia pendidikan. Peran pemerintah memang juga sangat diperlukan untuk menumbuhkan industri kreatif ini.

\section{Dunia Pendidikan Animasi}

Dunia akademis adalah dunia dimana kita bisa saling berbagi ilmu pengetahuan untuk memperkaya ilmu bagi pemberi maupun yang diberi. Suatu ilmu pengetahuan yang diciptakan oleh orang lain akan dibagi dan akan dikembangkan oleh orang lain berdasarkan ilmu yang dia pelajari sebelumnya. Pembelajaran adalah sebuah proses komunikasi, antara pengajar sebagai komunikator dan siswa sebagai komunikan. Keberhasilan proses komunikasi ini tergantung dari berfungsinya masing-masing 
komponen tersebut. Keberadaan media akan mempengaruhi kejelasan pesan yang disampaikan, serta mampu meminimalisir gangguan (noise) yang akan mempengaruhi sehingga komunikasi pembelajaran menjadi tidak efektif [Cepi R., 2003]. Dalam pendidikan animasi, media dalam menyampaikan ilmu terdapat bermacam-macam. Dan dengan semakin berkembangnya ilmu pengetahuan, media umum yang dipakai dapat dinamakan adalah informasi teknologi dan komunikasi (ICT). Menurut UNESCO bahwa fungsi teknologi informasi dalam dunia pendidikan adalah "untuk memenuhi kebutuhan pendidikan yang selama ini belum terpenuhi". Kondisi "belum terpenuhi" disebabkan karena: (i) kesamaan akses terhadap sumber daya pembelajaran yang bermutu, disebabkan kondisi geografis; (ii) keterkinian atau tingkat kemutakhiran ilmu pengetahuan yang dipelajari; (iii) kemudahan dalam menyerap materi ajar, karena kebanyakan model pembelajaran yang masih bersifat monoton satu arah; (iv) hubungan materi yang dipelajari dengan konteks kehidupan, karena miskinnya contoh kasus atau terbatasnya referensi yang relevan dengan kebutuhan.

Pendidikan animasi dalam konteks teknologi informasi di atas dangat erat hubungan masalah yang ada. Untuk menyediakan bahan ajar tentang animasi, pendidik sangatlah kesulitan. Dimana dalam dunia animasi, buku-buku yang ada dan beredar kebanyakan adalah buku berbahasa asing. Dan buku berbahasa asing tersebut harganya sangatlah mahal. Buku penunjang pendidikan animasi yang dikarang atau diterbitkan oleh penerbit dalam negeri kebanyakan masih terbatas dengan sebuah buku tutorial dalam menggunakan perangkat lunak animasi. Selain itu keterbatasan teknologi internet (lambatnya akses) juga sangat dirasa menjadi penghambat siswa atau pengajar dalam memperoleh/belajar ilmu animasi.

Untuk memenuhi kebutuhan teknologi bidang komputer dan perangkat lunak, kendala dana sangatlah dirasakan dalam memutakhirkan ilmu pengetahuan yang akan dipelajari. Tentunya pengadaan teknologi untuk membuat sebuah film animasi ini tidaklah mudah dan murah. Untuk membuat film animasi dibutuhkan dukungan perangkat keras dan lunak dengan spesifikasi tertentu yang harganya sangatlah mahal. Apalagi pengadaan perangkat lunak yang ada sekarang ini selalu megalami update dan spesifikasi perangkat keras yang dibutuhkan juga akan semakin tinggi untuk memenuhi kebutuhan pembuatan animasi. Untuk dunia pendidikan, hal ini merupakan kendala tersendiri karena dana untuk pengadaan alat dan perangkat lunak kebanyakan sekolah sangatlah terbatas. Untuk memenuhinya terkadang tidak sedikit sekolah yang kepemilikan perangkat lunaknya merupakan hasil bajakan. Hal ini sangat tidak baik dampaknya untuk dunia pendidikan.

Perlakuan dalam pembelajaran akan sangat mempengaruhi terhadap pengalaman mengajar, semakin abstrak pengajaran dilakukan (ceramah, membaca) maka semakin susah pengalaman belajar akan diperoleh. Dengan

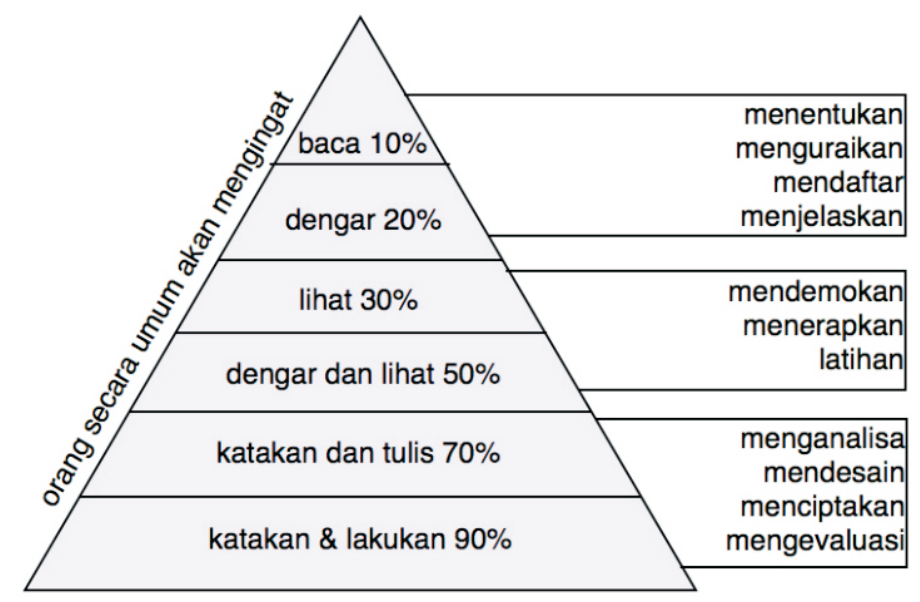

Gambar 1. "Kerucut pengalaman" Edgar Dale 
mengarahkan menggunakan media dan kegiatan langsung akan semakin cepat pengalaman belajar. Pengalaman tersebut mengacu pada bentuk "kerucut pengalaman" dari Edgar Dale yang secara luas digunakan dalam menentukan alat bantu yang paling sesuai dalam pembelajaran seperti terlihat pada gambar 1. Dalam pendidikan animasi, perlu diterapkan strategi pembelajaran yang siswanya harus langsung mempraktekkan dan melakukan apa yang diajarkan. Karena dalam pendidikan animasi, ranah kognitif yang menjadi pokok tujuan. Strategi dari pembelajaran adalah dengan melibatkan siswa secara langsung dalam praktek. Media instruksional yang dilakukan pengajar menyediakan ruang bagi siswa untuk melakukan praktek langsung menggunakan media yang dibutuhkan [Rogers, 2002].

Belajar animasi sekarang ini tidak lepas dari peranan teknologi perangkat lunak. Muncul banyak anggapan bahwa semakin mahal perangkat lunak yang bisa dipelajari, maka semakin mudah untuk mendapatkan pekerjaan di bidang animasi. Faktanya, di dunia industri animasi tidak hanya digunakan satu jenis/merk perangkat lunak. Industri animasi terkadang menggunakan beberapa jenis perangkat lunak 3D untuk mengerjakan proyek animasi. Bahkan banyak studio animasi yang mempunyai perangkat lunak khusus yang tidak dijual dipasaran.

Untuk belajar animasi khususnya 3D, dibutuhkan pengetahuan yang lebih sekedar penguasaan alat. Ketika seseorang sudah menguasai sebuah perangkat lunak 3D, dia akan bisa dengan cepat mengusai perangkat lunak 3D lainnya karena dasar-dasar pembuatan animasi 3D telah dia kuasai. Keberhasilan sebuah film animasi tidak tergantung pada seberapa canggih alat atau perangkat lunak itu digunakan, akan tetapi lebih pada hal-hal lain, seperti cerita, penokohan, adegan, dan lain-lain.

\section{Peran Teknologi Dalam Animasi}

Dua pengguna utama dalam dunia animasi adalah dunia pendidikan dan hiburan, yang kebutuhannya semakin hari semakin meningkat [Glenn \& al.]. Teknologi telah mengubah cara membuat dan memproduksi animasi. Semua pembuatan animasi sekarang telah melibatkan teknologi komputer, meskipun tidak sedikit yang masih menggunakan cara lama menggunakan gambar tangan seperti yang dilakukan oleh Walt Disney. Akan tetapi gambar manual juga tetap menggunakan sentuhan teknologi untuk memudahkan, mempercepat dan memperbaiki kualitas film animasi. Menurut Jean Underwood (2009) bahwa penelitian menunjukkan, penggunaan teknologi secara baik akan mempunyai dampak sebagai berikut: (i) efektifitas dan kinerja belajar meningkat, (ii) meningkatkan efisiensi dalam belajar, (iii) meningkatkan keterlibatan dan kepuasan pelaja, (iv) sikap pelajar menjadi positif dalam belajar.

Pada tahun 1980-an teknologi mempunyai pengaruh yang sangat besar terhadap perkembangan tentang bagaimana sebuah film animasi dibuat. Di tahun tersebut Steve Jobs dan Bill Gates telah menemukan dan mengembangkan teknologi revolusioner, sebuah peralatan komputer yang membuat hidup umat manusia sedikit mudah. Di tahun 1979 Studio Pixar hanya sebuah divisi kecil dari Lucas Film, akan tetapi pada tahun 1986 oleh Steve Jobs dibeli dan dikembangkan hingga menjadi perusahaan Pixar sampai sekarang bisa kita lihat kehebatannya. Sejak dirilisnya film Toy Story tahun 1995 oleh Pixar, sebuah film animasi yang dibuat penuh menggunakan komputer grafis menjadi tonggak awal dikenalnya film animasi komputer grafis. Sejak itu bermunculan film-film yang semuanya dibuat menggunakan komputer grafis seperti: The Incredibles, A Bugs Life (1998), Antz (1998), Dinosaur (2000), Finding Nemo (2003), Walle-E (2008) yang hampir semuanya memperoleh penghargaan sebagai film yang mempunyai tampilan grafis yang sangat menarik. Media distribusi film, khususnya animasi juga mengalami perubahan dengan berperannya teknologi. Mulai dari VHS, VCD, DVD, Blue Ray, sampai sekarang distribusi sudah melalui internet dengan membayar harga tertentu kita bisa mengunduh film yang kita inginkan dengan kualitas tertentu.

\section{Animasi Adalah Proyek Masa Depan}

Membuat animasi, walaupun itu animasi pendek mulai dari awal sampai selesai merupakan 
suatu hal yang sangat rumit, sebuah pekerjaan yang memerlukan banyak waktu (bahkan bisa dibutuhkan waktu 5 tahun untuk membuat film animasi). Diperlukan kemampuan yang tidak sembarangan untuk mengembangkan sebuah film animasi, salah satunya kemampuan penguasaan software. Sementara kemampuan yang lainnya juga harus menjadi perhatian, seperti: storytelling, manajemen aset dan manajemen waktu, akting dan juga editing. Jika kita menganggap salah satu dari aspek tersebut tidak penting, bisa dipastikan bahwa karya animasi kita akan menjadi kurang nilainya. Membuat film animasi memang memerlukan dedikasi yang tinggi, waktu luang, dan kemauan untuk menyelesaikan film tersebut, dan yang paling penting dari itu semua adalan rencana. Semua film animasi dibuat berdasarkan rencana yang dipikirkan sebelum produksi dengan matang. Kesalahan dan mungkin juga kegagalan dalam pembuatan film animasi biasanya adalah karena dilalui atau diabaikannya salah satu proses pembuatan animasi itu sendiri.

Kita sering langsung melompat kedalam proses produksi sebelum pasca produksi yang merupakan proses yang terpenting. Tanpa melalui proses pasca produksi (story telling, papan cerita, penetapan karakter, dan lain-lain) seperti halnya kita membangun rumah tanpa ada desain (blueprint). Kita langsung membangun pondasi, tembok sampai akhir. Hal ini memang sangat menyingkat pekerjaaan (atau malah membuat pekerjaan lebih lama), akan tetapi hasil yang dicapai tidak akan sebaik jika terdapat bentuk desain. Dalam beberapa tahun terakhir, teknologi animasi dan modeling 3D mengalami lompatan yang sangat besar dalam masalah ketersediaan dan "kekuatannya". Saat ini semua orang yang mempunyai personal komputer mempunyai kesempatan yang besar untuk menciptakan gambar 3D dengan kualitas yang baik.

Pengetahuan tentang prinsip-prinsip animasi, papan cerita, pengadeganan, menggambar pergerakan, karakter animasi, teknik animasi sel, timing, modeling, rigging, texturing, pencahayaan, rendering dan compositing merupakan ilmu-ilmu yang harus diajarkan dalam pendidikan animasi. Karena ilmu-ilmu tersebut merupakan bagian-bagian dari industri animasi global. Setiap perguruan tinggi atau sekolah kejuruan terkadang berbeda dan bervariasi dalam menerapkan kurikulumnya. Hal ini menunjukkan bahwa pengajar bidang animasi juga harusnya memiliki pengetahuan dan pemahaman yang baik tentang sektor industri animasi dan apa yang dibutuhkannya.

Dunia industri animasi memerlukan luluasan dari perguruan tinggi atau sekolah yang "siap pakai" sesuai dengan kompetensi dari siswanya. Bagian-bagian animasi yang telah disebutkan diatas merupakan bagian dari departemen pembuatan animasi. Yang semuanya itu, tiap orang yang ingin masuk ke dalamnya harus benar-benar menguasai bidangnya. Untuk bisa berkompetisi di dunia global, dunia pendidikan dan industri harus bisa bekerja sama dalam mengatasi masalah dan tantangan yang dihadapi sektor industri animasi, yang antara lain

1. Kurangnya jumlah industri yang berbasis kurikulum dalam akademik.

2. Kurangnya jumlah animator "siap pakai" dalam menghadapi dan menanggapi permintaan tinggi di sektor industri animasi.

3. Adanya jarak antara industri animasi yang membutuhkan kemampuan tertentu dengan sekolah atau pendidikan animasi yang ada.

4. Kurangnya sumber daya dari perusahaan kecil untuk melatih karyawan baru yang kurang terampil (mereka menginginkan karyawan yang langsung "siap pakai")

5. Pendekatan berbasis perangkat lunak melalui kursus yang ternyata jauh dari kebutuhan industri sebenarnya.

6. Harga dari perangkat keras dan perangkat lunak yang terlalu mahal (terutama perangkat lunak).

7. Kemauan dari industri animasi untuk bekerja sama berpartisipasi dalam meningkatkan industri animasi untuk dunia pendidikan sangat kurang.

8. Sangat dibutuhkan peran pemerintah dalam memajukan industri animasi.

\section{Blender dan Dunia Pendidikan}

Tujuan dari paper ini bukan menunjukkan bahwa Blender lebih baik dari perangkat lunak lainnya. Akan tetapi penulis mencoba memberikan gambaran bahwa Blender 3D bisa sebagai 
alternatif dalam media pembelajaran animasi tiga dimensi. Blender menyediakan semua fitur yang dibutuhkan untuk membuat super-realistis 3D model untuk animasi, film maupun game. Sebagai sebuah software open source, Blender tentunya bisa digunakan, didistribusikan ataupun dikembangkan sendiri sesuai kebutuhan pemakainya. Karena open source itulah maka Blender bisa diunduh secara gratis tanpa mengeluarkan sepeser biaya apapun. Selain itu perangkat lunak ini juga hadir dalam beberapa platform sistem operasi, mulai dari Windows, Mac OSX, Linux maupun Free BSD seperti terlihat dalam tabel 1 perbandingan beberapa perangkat lunak tiga dimensi. Perangkat lunak ini mampu dan lancar digunakan dalam mesin komputer kelas "low end" dan ukuran file nya juga terbilang sangat kecil (44 MB untuk Windows 64 bit dan 51 MB untuk Mac OSX Intel). Fitur lain yang hampir tidak dipunyai oleh perangkat lunak 3D lainnya game engine dan compositing.

\section{GL Graphics Card with 64 MB RAM.}

Perangkat lunak open source (free open source software FOSS) menawarkan manfaat yang sangat luar biasa bagi semua orang, terutama dalam bidang pendidikan. Dengan menggunakan FOSS, baik pendidik maupun siswa bisa mengembangkan kemampuan perangkat lunak yang juga dikembangkan oleh komunitas internasional. Dengan berkembangnya dunia internet, penggunaan FOSS yang dikembangkan oleh seluruh komunitas dunia sangatlah mudah dengan tersedianya tutorial dan sumber daya yang dibutuhkan lainnya. Selain itu juga memberikan setiap orang untuk bisa berkolaburasi dalam mengembangkan perangkat lunak melalui komunitas internasional. OSS juga mampu memberikan akses saluran, metode dan teknologi yang fleksibel untuk memberikan pengetahuan dan belajar ilmu pengetahuan secara terbuka. Kita bisa mendapati berbagai macam tutorial dari ribuan anggota komunitas.

\begin{tabular}{|c|c|c|c|c|c|}
\hline $\begin{array}{c}\text { Perbandingan } \\
\text { Perangkat } \\
\text { Lunak } 3 \\
\text { Dimensi }\end{array}$ & 3ds Max & $\begin{array}{l}\text { Autodesk } \\
\text { Maya }\end{array}$ & Blender 3D & Softimage XSI & Lightwave 3D \\
\hline Harga (mulai) & $\begin{array}{l}\$ 3,500.00 \\
\text { (USD) }\end{array}$ & $\begin{array}{l}\$ 3,500.00 \\
\text { (USD) }\end{array}$ & Gratis & $\begin{array}{l}\$ 495.00 \\
\text { (USD) }\end{array}$ & $\begin{array}{l}\$ 1,495.00 \\
\text { (USD) }\end{array}$ \\
\hline Platform & Windows & $\begin{array}{l}\text { Windows, Mac } \\
\text { OSX, Linux }\end{array}$ & $\begin{array}{l}\text { Windows, Mac } \\
\text { OSX, Linux, } \\
\text { FreeBSD }\end{array}$ & $\begin{array}{l}\text { Windows, } \\
\text { Linux }\end{array}$ & $\begin{array}{l}\text { Windows, } \\
\text { OSX, }\end{array}$ \\
\hline Penggunaan & $\begin{array}{c}\text { Modeling, } \\
\text { Animasi (Video } \\
\text { Game), } \\
\text { Lighting, } \\
\text { Rendering }\end{array}$ & $\begin{array}{c}\text { Modeling, } \\
\text { Animasi } \\
\text { (Video), } \\
\text { Lighting, } \\
\text { Rendering, } \\
\text { Visual 3D Efek }\end{array}$ & $\begin{array}{l}\text { Animasi, } \\
\text { Lighting, } \\
\text { Modeling, } \\
\text { Rendering, } \\
\text { Kreasi Video } \\
\text { Game, Visual } \\
\text { 3D Efek, } \\
\text { Sculpting, } \\
\text { Basic Post- } \\
\text { Production } \\
\text { Video Editing }\end{array}$ & $\begin{array}{c}\text { Modeling, } \\
\text { Animasi, } \\
\text { Kreasi Video } \\
\text { Game, } \\
\text { Lighting, } \\
\text { Rendering, } \\
\text { Visual 3d Efek }\end{array}$ & $\begin{array}{l}\text { Modeling, } \\
\text { Animasi, } \\
\text { Lighting, } \\
\text { Rendering, } \\
\text { Film, Previz } \\
\text { Televisi, Kreasi } \\
\text { Aset Video } \\
\text { game }\end{array}$ \\
\hline
\end{tabular}

Tabel 1. Perbandingan aplikasi software animasi yang sering digunakan

Dengan Blender kita bisa membuat sebuah game 3D yang hadir secara realtime rendering. Fitur-fitur lain seperti rigging, modeling, rendering, UV unwrapping, raytrace rendering, fisik dan partikel serta sculpting merupakan fiturfitur sangat lengkap untuk sebuah perangkat lunak yang hadir secara gratis. Blender 3D menerapkan spesifikasi minimal untuk perangkat lunak: $1 \mathrm{GHZ}$ Single Core CPU; 512 MB RAM; 1024 x 768 px Display with 16 bit color; 3 Button Mouse; Open
FOSS menawarkan kelebihan yang dapat dirinci sebagai berikut [Tan, 2004] :

1. Biaya Murah. Masalah utama pengambilan keputusan dalam penggunaan teknologi di dunia pendidikan adalah anggaran. Dengan FOSS, anggaran hanya digunakan untuk pengadaan perangkat keras dan pemeliharaannya saja. Untuk perangkat lunak semuanya gratis.

2. Kehandalan, kinerja dan keamanan. Gratis saja 
tidaklah cukup jika tidak ditunjang dengan kehandalan, performa, kinerja dan tingkat keamanan dari perangkat lunak yang dipakai. Orang banyak beranggapan bahwa barang gratis biasanya tidak bisa diandalkan. Hal ini sangat bertolak belakang dengan prinsip FOSS (terutama Blender 3D) yang khandalan, performa, kinerja dan keamanannya bisa ditandingkan dengan perangkat lunak berbayar sekalipun.

3. Kapasitas jangka panjang. Upaya terpadu harus dilakukan untuk memastikan penggunaan FOSS dalam kurikulum sedapat mungkin. Agar siswa tidak hanya mengenal perangkat yang berbayar, akan tetapi terdapat pilihan yang luas untuk menggunakan FOSS. Penggunaan FOSS akan terbiasa jika dilakukan mulai dini.

4. Filosofi terbuka. Filosofi ini sejalan dengan tujuan akademis dalam penyebaran ilmu pengetahuan dan informasi. Kemajuan dalam dunia seni dan pendidikan adalah hasil dari berbagi ide, teori, pembelajaran dan penelitian.

5. Mendorong inovasi. Banyak munculnya inovasi teknologi dan ilmu pengetahuan dan termasuk FOSS awalnya dikembangkan berasal dari dunia pendidikan. Di lingkungan pendidikan dimana FOSS secara lazim digunakan akan mendorong staf dan siswa untuk mengembangkan FOSS yang akhirnya mengarah pada solusi inovatif.

6. Alternatif dari pembajakan. Institusi pendidikan yang tidak mampu untuk membeli perangkat lunak berbayar bisa menggunakan FOSS sebagai alternatif. FOSS bisa digunakan, disebarluaskan, digandakan berapapun yang dibutuhkan. Jika dunia pendidikan menggunakan perangkat lunak perbayar, mau tidak mau pekerjaan rumah yang dikerjakan siswa akan menggunakan perangkat lunak yang berbayar pula. Jika siswa tidak mampu membelinya, mereka secara otomatis akan membajaknya.

7. Belajar dari source code. Pengguna FOSS bisa memodifikasi ulang sesuai dengan kebutuhannya. Hal ini menjadikan siswa mempunyai kesempatan untuk belajar kode sebuah pemrograman yang baik untuk membuat sebuah perangkat lunak. Dan bahkan jika kita bisa memodifikasi sehingga mempunyai kemampuan atau kinerja lebih baik, kita juga bisa menjual hasil modifikasi FOSS tersebut tanpa harus membayar lisensi sepeserpun.

8. Kemungkinan pelokalan, FOSS biasanya hadir dalam bahasa Inggris. Untuk negara yang menggunakan bahasa selain Inggris bisa memodifikasi FOSS nya menggunakan bahasa sesuai yang diinginkan. Biasanya hal ini dilakukan untuk lebih mempercepat proses belajar dari FOSS tersebut.

\section{Open Movie}

Untuk menunjukkan dunia animasi bahwa Blender sebagai perangkat lunak open source mampu membuat film animasi berkelas internasional, maka Blender Institut mulai membuat open movie. Keseluruhan proyek open movie ini diproduksi oleh FOSS yang utamanya adalah Blender 3D. Disebut sebagai Open Movie karena semua orang bisa mendownload selain filmnya, juga file-file "mentahan" mulai dari karakter model, sampai environment model, dan hampir semua properti dalam film bisa diunduh melalui websitenya dan bebas untuk mendistribusikan atau menggunakan ulang bahkan untuk keperluan komersial. Dengan diproduseri oleh pencipta sekaligus ujung tombak dari Blender, Tom Rossendaal. Blender Institut mengumpulkan orang-orang yang bertalenta dari forum Blender untuk mengerjakan projek open movie di Amsterdam dalam waktu minimal setengah tahun.

\section{Elephants Dream (2005)}

Blender memukau seluruh dunia dengan munculnya sebuah Open Movie pertama di dunia berjudul Elephants Dream. Proyek ini dinamakan Project Orange, Elephants Dream mulai diproduksi September 2005 dan ditayangkan resmi pada Maret 2006. Film ini menceritakan tentang dua karakter yang menjelajah sebuah dunia yang tersusun dari mesin. Menurut websitenya adalah cerita tentang dua karakter berbeda yang menjelajah dunia mesin yang selalu berubah dan tampak tak terbatas. Karakter yang tua bernama Proog, bertindak sebagai pemandu dan pelindung yang menunjukkan pemandangan 
dan bahayanya mesin kepada anak didiknya Emo yang skeptis. Setelah menjelajah, ternyata mesin tidak seperti yang dipikirkan oleh Proog. Film ini berdurasi 10 menit dan memerlukan waktu 1 tahun dalam pembuatannya dan melibatkan 6 orang untuk membuatnya.

(http://www.elephantsdream.org)

\section{Big Buck Bunny (2007)}

Dikenal dengan Project Peach, open movie kedua yang diproduksi mulai Oktober 2007 dan ditayangkan resmi pada April 2008. Film ini tentang seekor kelinci raksasa yang sedang bahagia di pagi hari dan diganggu oleh tiga tupai nakal. Film ini dibuat oleh 7 orang 3D artis yang tergabung dalam komunitas blender. Target utama film ini adalah dengan mengekspos kemampuan Blender: (1) dalam menciptakan rambut, fur dan rumput; (2) meningkatkan dalam penggunaan karakter animasi; (3) mengimplementasi lingkungan outdoor yang luas dengan bidang rumput yang luas dan pepohonan dengan daunnya yang lebat; (4) menunjukkan bahwa blender mampu membuat film animasi secara profesional. Film ini dibawah lisensi Creative Commons Attribution 3.0 yang artinya semua konten yang dihasilkannya bisa digunakan dan didistribusikan ulang bahkan untuk penggunaan komersial.(http://www.bigbuckbunny.org)

\section{Yo Frankie! (2008)}

Selain menghasilkan open movie, Blender Institut juga membuat sebuah open game yang konsepnya hampir sama dengan open movie. Dinamai Project Apricot, open game ini mulai diproduksi pada Februari 2008 dan resmi diumumkan pada September 2008. Pemain dalam game ini memerankan seekor tupai nakal Frankie yang menjelajah hutan mencari hewan lain untuk diganggu. Target dari pembuatan game ini adalah untuk memperlihatkan bahwa Blender game engine juga patut menjadi perhitungan. Game full 3D ini memperlihatkan kehebatan Blender dalam membuat dan langsung merender real time sebuah game.(http://www.yofrankie.org)

\section{Sintel (2010)}

Open movie ketiga, Project Durian dimulai pada September 2009 dan ditayangkan secara premier di Netherland Film Festival pada akhir bulan september 2010. Film ini berdurasi 15 menit dibuat menggunakan blender versi 2.5. Film ini mengekspos kemampuan blender dalam: (1) membuat api, asap, volumetric dan ledakan; (2) compisiting menggunakan tiles/region, yang hasilnya rendernya mempunyai resolusi yang mandiri; (3) simulasi kerumunan/crowd (sistem animasi fix yang bisa diduplikat); (4) modeling dengan tingkat detail yang tinggi (sculpting) dan render micro polygon.(http://www.sintel.org)

\section{Tears of Steel (2012)}

Berdasarkan open movie sebelumnya, projek Mango ini ingin membuat berbeda, yaitu : membuat visual efek (vfx) film pendek menggunakan aktor sungguhan dan tema utamanya adalah Sci-Fi Amsterdam. Dengan demikian open movie ini mempunyai target teknis antara lain : (1) kamera dan motion tracking, (2) render foto realistis, (3) memperbaiki pipeline warna, (4) memperbaiki compositing, editing video efek, masking dan grading, (5) membuat api, asap, volumetrik dan efek ledakan, (6) memaksimalkan deps-graph dalam Blender.(http://www.mango.blender.org)

Setiap proyek open movie mulai dari Orange, Peach, Apricot, Durian dan terakhir Mango oleh Blender Fondation mempunyai tujuan kedepan antara lain :

1. Menstimulasi pengembangan Blender 3D ketingkat yang lebih tinggi sebagai perangkat lunak penghasil karya animasi secara profesional.

2. Sebagai bukti kepada seniman animasi bahwa Blender mampu secara profesional membuat film tingkat internasional.

3. Menggunakan dan terus memperbaiki pipeline dari sebuah open source.

4. Memberikan pesan positif bagi Blender bagi seluruh masyarakat dunia.

5. Membuat presentasi yang berharga dan berguna untuk dunia pendidikan dalam bentuk Open Content.

6. Memberikan pengalaman yang menyenangkan dan sebuah inspirasi yang baik untuk seluruh komunitas Blender. 


\section{Kesimpulan}

Blender sebagai free open source software memang sejalan dengan misi pendidikan yang mengembangkan ilmunya secara terbuka. Namun, penguasaan perangkat lunak untuk mempelajari animasi bukanlah suatu hal sangat mendasar. Perangkat lunak adalah alat untuk membuat film animasi secara visual lebih menarik dan meyakinkan. Terdapat hal-hal lainnya yang perlu dipelajari dalam pendidikan animasi.

Selain itu peran pendidik juga sangatlah penting dalam pengembangan ilmu animasi. Pendidik juga harus tahu perkembangan di dunia animasi agar alam memberikan pengetahuan kepada siswa relevan dengan keadaan sekarang maupun kedepan. Karena animasi dan pembuatannya membutuhkan sumber daya manusia yang banyak dan kompleksnya ilmu yang akan dipelajari, perlu bagi setiap institusi pendidikan memiliki kompetensi tertentu bagi anak didiknya. Dalam animasi tidak ada satu orang yang menguasai semuanya. Satu orang biasanya ahli dalam satu bagian dari animasi. Sekolah atau institusi seharusnya tidak mencetak siswa yang bisa semuanya "superman". Karena di bidang industri yang dibutuhkan adalah orang-orang di bagian/departemen tertentu dalam pembuatan animasi.

Pemerintah sebagai pilar utama dalam pengembangan industri kreatif juga harus lebih memperhatikan animasi secara penuh. Seperti yang dilakukan negara-negara lain seperti Malaysia, Singapura dan Filipina, pemerintah negara-negara tersebut membuat kebijakankebijakan dan bantuan terutama bidang pendanaan untuk lebih menumbuhkan bidang animasi. Tanpa dukungan pemerintah, animasi Indonesia terasa akan jalan ditempat. Dan lebih parahnya lagi, animator-animator terbaik Indonesia akan "lari" keluar negeri agar memperoleh penghargaan yang pantas disana. Imbasnya adalah yang berkembang justru malah animasi negara lain yang berkembang, sedangkan di Indonesia akan semakin tertinggal.

\section{Daftar Pustaka}

Riyana, Cepi., "Media Pembelajaran", Jurusan Kurikulum Dan Teknologi Pendidikan, FIP - Universitas Pendidikan Indonesia, 2003

Rogers, Patricia L, "Designing Instruction for Technology-Enhanced Learning", Idea Group Publishing. 1331 E. Chocolate Avenue Hershey PA 17022-1117, 2002

Sipin, Glenn L., Espiritu, Jose L.D., Malabanan, Oliver A., "Issues On The Philippines' Information And Communications Technology (ICT) Competitivenes".

Studi Industri Kreatif Indonesia, 2007 bagian 2

Tong, Tan Wooi, "Free/Open Source Software Education", Reed Elsevier India Private Limited, 2004

Underwood, Jean., "The impact of digital technology", Millburn Hill Road Science Park Coventry CV4 7JJ, 2009

\section{Pertautan}

http://www.elephantsdream.org http://www.bigbuckbunny.org http://www.yofrankie.org http://www.sintel.orghttp://www.mango.blender. org 